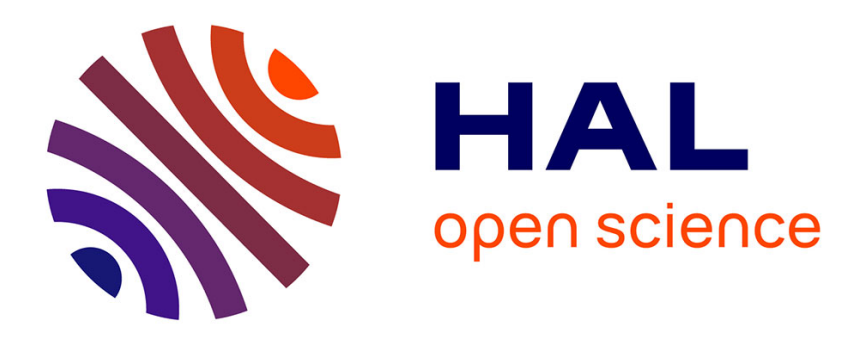

\title{
Validation of transient cooling modeling for hypersonic application
}

Nicolas Gascoin, Philippe Gillard, Emmanuel Dufour, Youssoufi Touré

\section{To cite this version:}

Nicolas Gascoin, Philippe Gillard, Emmanuel Dufour, Youssoufi Touré. Validation of transient cooling modeling for hypersonic application. Journal of Thermophysics and Heat Transfer, 2007, 21 (1), pp.8694. 10.2514/1.26022 . hal-00641620

\section{HAL Id: hal-00641620 \\ https://hal.science/hal-00641620}

Submitted on 16 Nov 2011

HAL is a multi-disciplinary open access archive for the deposit and dissemination of scientific research documents, whether they are published or not. The documents may come from teaching and research institutions in France or abroad, or from public or private research centers.
L'archive ouverte pluridisciplinaire HAL, est destinée au dépôt et à la diffusion de documents scientifiques de niveau recherche, publiés ou non, émanant des établissements d'enseignement et de recherche français ou étrangers, des laboratoires publics ou privés. 


\title{
Validation of Transient Cooling Modeling for Hypersonic Application
}

\author{
Nicolas Gascoin* and Philippe Gillard \\ Université d'Orléans, 18000 Bourges, France \\ Emmanuel Dufour \\ MBDA-France, 18000 Bourges, France \\ and \\ Youssoufi Tourés \\ Université d'Orléans, 18000 Bourges, France \\ DOI: $\underline{10.2514 / 1.26022}$
}

\begin{abstract}
Hypersonic flight is expected to be achieved in the coming years by use of supersonic combustion ramjet. One of the main issues is the thermal management of the overall vehicle and more specifically the cooling of the engine. To simulate the behavior of an actively cooled supersonic combustion ramjet by use of supercritical endothermic fuel, a one-dimensional transient numerical model has been developed with heat and mass transfer, fluid mechanics and detailed pyrolysis chemistry. A supplementary step by step validation of the model is presented in this paper thanks to numerical and experimental comparison test cases. Fluid temperature profiles are in good agreement for steadystate calculations despite unconsidered 2-D effects due to momentum and thermal boundary layers. Heat fluxes conservation is verified. Thermal and hydraulic transient behavior are close to those of validation data. The present numerical modeling is quantitatively validated under steady state and transient conditions. Good agreement is found with experimental results on a chemical aspect. The model is suitable for conducting parametric studies on fuel pyrolysis in supercritical states and to use it for engineering applications as a predimensioning tool.
\end{abstract}

\begin{tabular}{lll} 
& & \multicolumn{1}{c}{ Nomenclature } \\
$A$ & $=$ & surface \\
$C_{f}$ & $=$ & friction coefficient \\
$c$ & $=$ & sound velocity \\
$c_{p}$ & $=$ & heat capacity \\
$D_{H}$ & $=$ & hydraulic diameter \\
$e$ & $=$ & wall thickness \\
$e e$ & $=$ & length between two pin fins \\
$F$ & $=$ & view factor \\
$G r$ & $=$ & Grashof number \\
$H$ & $=$ & total enthalpy \\
$h$ & $=$ & convective heat transfer coefficient \\
$h_{\text {can }}$ & $=$ & height of the channel \\
$h_{i, 0}$ & $=$ & static enthalpy at $298 \mathrm{~K}$ of $i$ species \\
$j$, & $=$ & conduction flux density \\
$\dot{m}$ & $=$ & mass flow rate \\
$N u$ & $=$ & Nusselt number \\
$P$ & $=$ & pressure \\
$p$ & $=$ & perimeter
\end{tabular}

Presented as Paper 4028 at the 4th International Energy Conversion Engineering Conference and Exhibit (IECEC), San Diego, California, 26-29 June 2006; received 21 June 2006; revision received 29 August 2006; accepted for publication 29 August 2006. Copyright $\odot 2006$ by the American Institute of Aeronautics and Astronautics, Inc. All rights reserved. Copies of this paper may be made for personal or internal use, on condition that the copier pay the $\$ 10.00$ per-copy fee to the Copyright Clearance Center, Inc., 222 Rosewood Drive, Danvers, MA 01923; include the code $\$ 10.00$ in correspondence with the CCC.

*Ph.D., Laboratoire Energétique Explosion Structure, IUT de Bourges, 63 , avenue de Lattre de Tassigny, 18020 Bourges Cedex, France; Nicolas.Gascoin@bourges.univ-orleans.fr. AIAA Member.

${ }^{\dagger}$ Professor, Laboratoire Energétique Explosion Structure, IUT de Bourges, 63, avenue de Lattre de Tassigny, 18020 Bourges Cedex, France; Philippe.Gillard@bourges.univ-orleans.fr.

*Numerical Simulations Engineer, MBDA-France, 8 rue Le Brix; emmanuel.dufour@mbda.fr.

§Professor, Laboratoire Vision \& Robotique, IUT de Bourges, 63, avenue de Lattre de Tassigny, 18020 Bourges Cedex, France; Youssoufi.Toure@bourges.univ-orleans.fr.

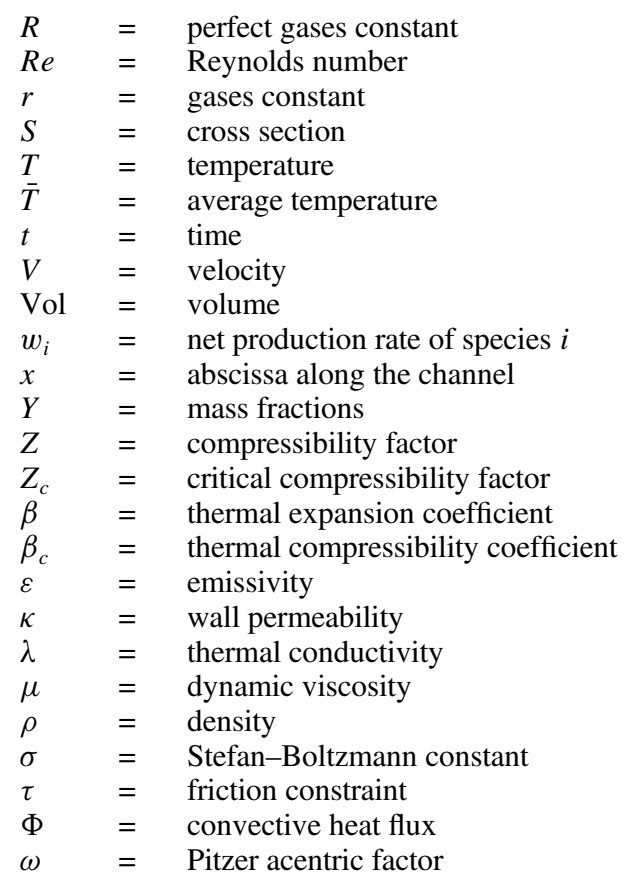

Subscripts

$\mathrm{CC}=$ combustion chamber

$\mathrm{cw}=$ cold face (of the porous wall)

ef $=$ external face (of the external wall)

ew $=$ external wall

ext $=$ external environment

$f \quad=\quad$ fluid

$\mathrm{fm} \quad=$ film

hw $=$ hot face (of the porous wall)

$i=$ species

if $\quad=\quad$ internal face (of the external wall)

pw $=$ porous wall 


$\begin{array}{lll}s & = & \text { static } \\ y & = & \text { orthogonal direction to } x \text { abscissa } \\ 0 & = & \text { standard conditions at } 298 \mathrm{~K}\end{array}$

Superscripts

$(0)=$ first tabled value

(1) $=$ second tabled value

$+\quad=\quad$ reduced coordinates (i.e., divided by the critical value)

\section{Introduction}

$\mathbf{H}$ YPERSONIC flight [1,2] is expected to be achieved with dualmode ramjet, that is, ramjet under Mach 6 and supersonic combustion ramjet (scramjet) $[3,4]$ beyond, because of its high specific impulse and its capability to be reusable [ $[5,6]$. The latter point is especially interesting for space transportation. Because the total temperature of external air reaches temperatures as high as $4950 \mathrm{~K}$, for example, at Mach 12, even composite materials could not withstand such a large heat load. Thus, an active cooling system has to be used but not a dedicated one so as not to increase the vehicle weight. Furthermore [7], the time allocated to mix the injected fuel with incoming air, to ignite the combustion, and to complete it before the chamber outlet is about $10^{-3} \mathrm{~s}$. These two points lead us to use the fuel to cool down the engine's wall and then to burn it in the combustion chamber (CC). This solution is called regenerative cooling. Different cooling strategies have been evaluated by the MBDA-France company and its partners with calculations [8] and material tests [9-11]. The present work falls within the framework of the COMPARĒR project (a French acronym for control and measure of parameters in a reacting stream).

The principle of scramjet technology, its advantages, and the interest to use hydrocarbon fuel to cool down the engine have been fully studied in the literature [12-15]. Compared to cryogenic hydrogen, heavy hydrocarbon fuels are safer and much simpler to use, their costs are lower, and they conduct to smaller vehicles because their density is higher than that of cryogenic fuels. For the cooling strategy adopted here [16], liquid $n$-dodecane is injected near the outlet of the CC in a composite channel [10] which surrounds the engine. It flows to the injection in counterflow to the burned gases. When heated above $800 \mathrm{~K}$, the fuel is pyrolyzed and thanks to its endothermic behavior, it ensures the regenerative active cooling of the hot CC walls. This pyrolysis produces lighter hydrocarbon species, such as hydrogen, methane, and ethylene, which are easier to ignite. This allows for responding to rapid phenomena inside the CC. It is important to note that the expected high pressure in the cooling loop ( $>3 \mathrm{MPa}$ ) causes the fluid to become supercritical in the channel, which leads to some difficulties such as fluid property evaluation and flow rate measurement.

The injected mass flow rate is expected to be slightly lower than the one pumped from the tank because of film cooling through porous walls and of carbon deposits due to coke formation at temperatures higher than $900 \mathrm{~K}$. This last phenomenon will also change the carbon/hydrogen ratio of the fuel in the channel. This point needs to be studied because it influences the combustion and the thrust. To have an idea of coking activity during pyrolysis, a typical stainless steal reactor, used on the experimental test bench presented in this paper, is completely jammed by coke after $5 \mathrm{~h}$ at $1000 \mathrm{~K}$ with $0.05 \mathrm{~g} \cdot \mathrm{s}^{-1}$. It has an internal diameter of $4.5 \times 10^{-3} \mathrm{~m}$.

The control of fuel pyrolysis and its combustion is required to manage the thrust and to predict heat fluxes. Controlling the engine may not be trivial because to increase the thrust, it would be obvious to increase the fuel mass flow rate. But for the same heat flux applied to the cooling channel, this would imply a lower pyrolysis, which corresponds to a less energetic injected fuel composition. Thus, the thrust would be lower and scramjet could even be finally shut down. A strong relationship is identified between cooling and propulsion. A dedicated numerical tool is necessary to study this point and to understand interactions between phenomena related to the regenerative active cooling.
A review of scramjet activities has been done to determine if some of them are related to the identified need. The fields of research on scramjet technology are numerous. Experimental studies are necessary to prove and to test the feasibility of this propulsion engine but the facilities requirements for ground or in-flight tests are very heavy $[17,18]$. Scramjet tests are particularly difficult due to imposed security and consequent costs. Therefore, modeling is a more feasible method for conducting engineering studies and for furthering research related to this topic even if experiments still improve knowledge and furnish validation data for numerical studies [19].

Numerical activities mainly focus on complex phenomena involved in the $\mathrm{CC}$ [20] or in the nozzle [19]. Combustion is of great interest because of supersonic flow and its impact on turbulence, chemical reactions, flame stability, heat transfer, and engine thrust. The active cooling of the engine and that of the overall vehicle have been well studied $[21,22]$ and the effect of film cooling on the thrust has been investigated [23]. The modeling of thermal exchange between the overall vehicle and the outer air of the environment has been treated [24]. Whereas the main available studies about scramjet are focused on specific points, only a few studies $[25,26]$ are dedicated to the whole cooled propulsion system. Unfortunately, a simple 0-D approach is used. As the pyrolysis and combustion chemistry is never treated, coupled phenomena are not considered and the relationship between fuel composition and scramjet thrust cannot be taken into account. The need of a specific tool considering the overall vehicle, its cooling as its thrust, is thus evident to study the entire coupled phenomena involving the scramjet cooled technology. This tool should not be only a research tool with a high level of computation cost but it should be suitable for daily use by engineers.

If computational fluid dynamics (CFD) is becoming a powerful simulation tool [27], adapted to all fields of scramjet [28] research, this kind of simulation has some major drawbacks. $\overline{C F D}$ has been successfully applied to the CC [29-31], but combustion chemistry of the reacting flow is not often taken into account. For some 2-D calculations, that is only conducted with a few species and a tenth of a combustion reaction. Reduced chemical mechanisms are often used. For example, Mitani and Kouchi [32] present their steady-state model running on a parallelized cluster of 64 processors ( 8 GFlops/ CPU). One calculation needs more than $600 \mathrm{~h}$ and it considers 17 reactions and nine species. This highlights the fact that CFD cannot be suitable for complete transient simulation with chemistry effects, particularly as an engineering tool on a single computer.

Very accurate values inside the system are not needed for the COMPARER project. For example, a fluid temperature profile inside the 3-D CC and fluid velocity in the boundary layer along the cooling channel are not of great interest. The purpose of the developed model is not to fully and very accurately follow phenomena involved in the engine cooling. The aim is mainly to understand the relationships between phenomena. This code should be suitable for testing a cooling strategy which depends on various parameters such as engine thrust and hot wall temperature. The accuracy aimed in the modeling is to determine temperatures to a tenth of a degree and the chemical composition at a mole fraction of about $1 \%$.

The proposed modeling is called RESPIRE (a French acronym for scramjet cooling with endothermic fuel, transient reactor programming). It uses a full $n$-dodecane pyrolysis mechanism (1185 reactions and 153 species, designed by the French laboratory DCPR) [33]. This model is the minimum one which is able to successfully predict the thermal decomposition. Most of the radical species, which have minimal concentrations in the mixture, play a determining role in the production and consumption of all other species. Mixtures have never been found to be at a thermodynamic state because of high heat flux and low residence times. Furthermore, all species must be considered in order to predict their combustion. Chemical composition cannot be given by data tables depending on fluid temperature or pressure. Because the pyrolysis depends on the entire working conditions, its computation needs to be done with a detailed chemistry mechanism in relationship to thermal and hydraulic calculations. Notably, Ward et al. [34] are working on 
pyrolysis in a chemical reactor under a supercritical state, but they only consider a reduced mechanism which does not lend itself well to studying either the cooling management or the relationship between composition and combustion of the fuel.

Calculations of fluid properties in the RESPIRE code have been presented and validated in previous work for viscosity and thermal conductivity [35], in addition to heat capacity and density [36]. If the properties of pure fluid are considered and not that of pyrolyzed fluid, fluid temperatures at the cooling channel outlet are about $20 \%$ higher. This is due to the heat capacity which varies until a factor 2 . This results in a completely different fluid composition and combustion, which justifies its consideration. Transient conduction through channel walls has been investigated [37] using steady state and transient heat flux conditions. Less than a $2 \%$ variation on wall temperature, compared to analytical data, has been found with steady-state heat flux. The transient heat flux shows a slight time shift of wall temperature, probably because of the use of average wall temperature to determine the face temperatures. The method used to compute the chemical fluid composition has been validated [36,37]. Compared to an experimental test with NORPAR-12 fuel, the $n$ dodecane pyrolysis gives relatively good agreement, typically a $3 \%$ variation in terms of mole fraction. Further validations of fluid temperature have been briefly presented in [37].

The purpose of this paper is first to give formulation of heat and mass transfer in a heated channel fueled with reacting endothermic fuel flow, potentially in a supercritical state. Secondly, the in-depth validation proposed here provides thermal and hydraulic data compared to numerical results obtained with the commercial software CFD-ACE. This one has been validated and tested in [38], and good agreement was found. Moreover, differences are identified and explained. This comparison has the main advantage of determining how each phenomenon related to the cooling channel is taken into account. Programming bugs are easier to find. Experimental data are too difficult to obtain for hydraulic and fluid heating validations as time-dependent flow velocity and temperature are not measurable inside the channel. To validate the chemical part of the RESPIRE code, experimental data coming from the COMPARER test bench are suitable because this one allows for obtaining pyrolyzed fluid samples to be obtained under various controlled conditions.

\section{Governing Equations of the Full Transient Model}

The main equations resolved by RESPIRE are presented in the following section. This code is based on knowledge acquired by MBDA-France, validated and used by steady-state FORTRAN codes (for example, the NANCYNETIK modeling [35]). The present code, programmed under MATLAB, integrates some parts with a transient and a more detailed approach.

\section{A. Geometry of the Cooling Channel and Modeling Assumptions}

A scramjet engine is considered with a rectangular section (Fig. 1). The cooling channel is detailed in Fig. 2. Each wall, the external one and the porous one linked together by numerous pin fins, is in contact with a different environment, such as outside the vessel and inside the combustion chamber. Because RESPIRE is a 1-D code, all variables are constant on a cross section of the fluid or of the material. The fluid

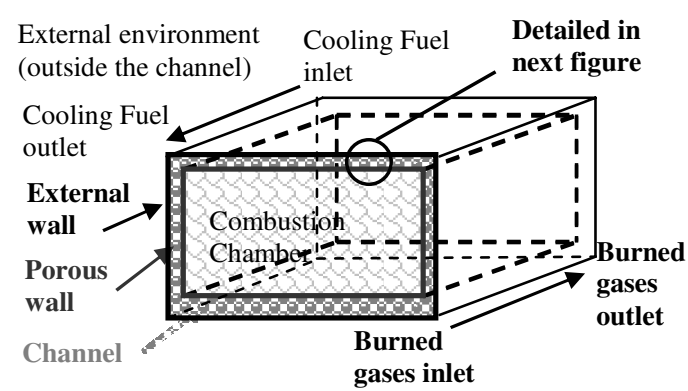

Fig. 1 Generic representation of a cooled scramjet engine.

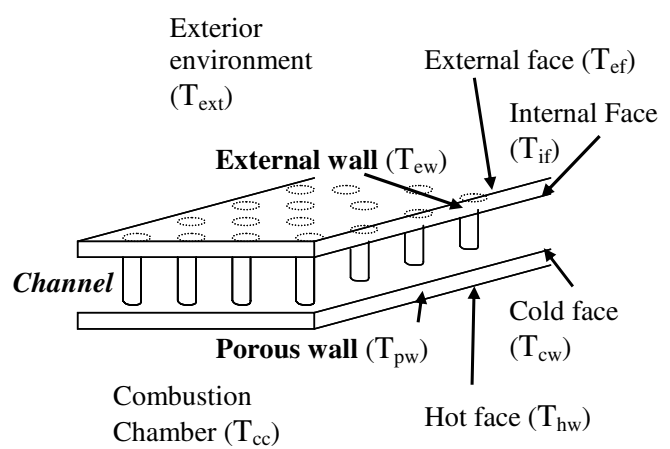

Fig. 2 Identification of different cooling channel parts.

is considered to be homogeneous on each slice along the flow, and it is treated as an average single phase flow but possibly multispecies.

Equations are written in a transient state and the resolving method is a finite differences one. Partial derivative equations are discretized in space with a centered explicit scheme and then solved in time with an explicit scheme. The spatial step is of the order of $5 \times 10^{-3} \mathrm{~m}$, and the time step is chosen on behalf of the flow velocity expected in the channel so as to keep a particle inside a given spatial step between two time steps.

When use of the model is made for calculating the full engine, a flight configuration is chosen, especially the altitude, the flight velocity, and the vehicle's position. All geometrical data, such as the flow cross section, the length, and the width are defined. Initial conditions, those of a steady-state case, are given. Boundary conditions are just the flight conditions, like the environment, because all needed variables are calculated inside the vehicle and engine. The cooling channel may be considered alone, that is, without considering combustion phenomena and vehicle flight conditions. This allows for calculating only fuel pyrolysis and heat/ mass transfers involved in the channel. Thus, additional boundary conditions, such as heat flux, have to be provided.

\section{B. Heat Transfer in External and Porous Walls}

This section presents the equations for face and wall temperatures when the external environmental conditions are given. Because of the Biot number lower than 0.1, the thermal gradients in walls are supposed to be linear. An average temperature $\bar{T}_{w}$ is computed in the wall, considering radiative, convective, and conductive heat fluxes. The two faces temperature of each wall are then deduced. For example, Eqs. (1a) and (1 1 b) allow one to determine, respectively, $T_{\text {ef }}$ and $T_{\text {if }}$ for the external wall $\left[\bar{T}_{\text {ew }}=\left(T_{\text {ef }}+T_{\text {if }}\right) / 2\right]$. The same kind of expressions [39] are used to compute temperatures in porous walls [and $T_{\mathrm{cw}}$ with $\bar{T}_{\mathrm{pw}}=\left(T_{\mathrm{hw}}+T_{\mathrm{cw}}\right) / 2$ ] but in this case, radiative heat transfers between walls are not considered inside the combustion chamber because of its squared geometry. Each wall receives as much energy as it emits. Because of low discrepancies between walls and gas temperatures, the radiative transfer from the gas to the walls is linearized and it is integrated in the convection coefficient to compute the hot wall temperature $T_{\mathrm{hw}}$. To write Eqs. (1a) and (1b), convection with the cooling fluid at the surface of the walls is considered to be equal to conduction into these walls.

$$
\begin{aligned}
& \frac{\partial \bar{T}_{\mathrm{ew}}}{\partial t}=\frac{1}{\rho_{\mathrm{ew}} c_{p \mathrm{ew}}\left(e_{\mathrm{ew}} A_{\mathrm{ew}}\right)}\left[h_{\mathrm{ew}-\mathrm{ext}} A_{\mathrm{ew}}\left(T_{\mathrm{ext}}-T_{\mathrm{ef}}\right)\right. \\
& \left.+\varepsilon \sigma A_{\mathrm{ew}} F_{\mathrm{ew}-\mathrm{ext}}\left(T_{\mathrm{sext}}^{4}-T_{\mathrm{ef}}^{4}\right)+\lambda_{\mathrm{ew}} A_{\mathrm{ew}}\left(\frac{T_{\mathrm{if}}-T_{\mathrm{ef}}}{e_{\mathrm{ew}}}\right)\right] \\
& \frac{\partial \bar{T}_{\mathrm{ew}}}{\partial t}=\frac{1}{\rho_{\mathrm{ew}} c_{p \mathrm{ew}}\left(e_{\mathrm{ew}} A_{\mathrm{ew}}\right)}\left[\lambda_{\mathrm{ew}} A_{\mathrm{ew}}\left(\frac{T_{\mathrm{ef}}-T_{\mathrm{if}}}{e_{\mathrm{ew}}}\right)\right. \\
& \left.-h_{f-\mathrm{if}} A_{\mathrm{ew}}\left(T_{\mathrm{if}}-T_{f}\right)\right]
\end{aligned}
$$


$h_{f-\mathrm{if}}$ is considered at the following film temperature: $T_{\mathrm{fm}}=\left(T_{f}+\right.$ $\left.T_{\text {if }}\right) / 2$ and is given by $h=\left(N u \times \lambda_{\text {fm }}\right) / D_{H}$ with $D_{H}=$ $\left(2 \times e e \times h_{\text {can }}\right) /\left(e e+h_{\text {can }}\right)$, where turbulent semi-empirical formulas are used for Reynolds number (Colebrook formula [40] with pin fins), Prandtl number, and Nusselt number (Colburn correlation with tube in quincunx [40]).

\section{Equations for Fluid Flow Inside the Cooling Channel}

In this section, $V_{f}$ is determined by the momentum equation [Eq. (2)] and $H_{f}$ by the energy equation [Eq. (3)]. In Eq. (3), the term $\partial\left(\rho_{f} \bar{V}_{f}\right) / \partial t$ can be written as $\rho_{f} \partial V_{f} / \partial t+V_{f} \bar{\partial} \rho_{f} / \partial t$. Consequently [39], a continuity equation is used to write

$$
\frac{\partial\left(\rho_{f} V_{f}\right)}{\partial t}=\rho_{f} \frac{\partial V_{f}}{\partial t}+V_{f} \frac{\partial \rho_{f}}{\partial t}=\rho_{f} \frac{\partial V_{f}}{\partial t}-V_{f}\left(\frac{\partial\left(\rho_{f} V_{f}\right)}{\partial x}\right)
$$

The fluid is considered to exchange with walls by convection only. Equations (2) and (3) are given without the effusion term through the porous wall because no validation has presently been conducted on this point. An equation of state $(P / \rho=Z r T)$ is used to determine density $\left(\rho_{f}\right)$ considering the compressibility factor $Z=Z^{+(0)}+$ $\omega Z^{+(1)}$ with $\omega=\left(0.2901-Z_{c}\right) / 0.0879$ the Pitzer acentric factor. The Lee-Kesler tables [41] are needed for $Z^{+(0)}, Z^{+(1)}$ and to correct the heat capacity on behalf of temperature and pressure. This approach is adapted to the pressure range and allows for representing the supercritical part of the fluid flow inside the channel. The pressure of the fluid is determined by use of a bulk modulus $[42,43] \beta=$ $\partial P /(\partial \rho / \rho)$ with $\beta=\rho c^{2}$. Buoyancy is not taken into account if the Grashof number divided by the squared Reynolds number is lower than unity $\left(G r / R e^{2} \ll 1\right)$. For a typical liquid fluid flow (under $600 \mathrm{~K}$ ) inside the cooling channel, $G r / R e^{2}>1$.

$$
\begin{gathered}
\frac{\partial\left(\rho_{f} V_{f}\right)}{\partial t}+\frac{\partial\left(\rho_{f} V_{f}^{2}\right)}{\partial x}=-\frac{\partial P_{s f}}{\partial x}+\frac{\partial \tau}{\partial x} \\
\frac{\partial\left(\rho_{f} H_{f}\right)}{\partial t}+\frac{\partial\left(\rho_{f} V_{f} H_{f}\right)}{\partial x}=\left(1-\beta_{c} T_{s f}\right) \frac{\partial P_{s f}}{\partial t}+\frac{\partial}{\partial x}\left(-j_{q}+V_{f} \tau\right) \\
+\rho \sum_{\text {especes }} h_{i, 0} w_{i}+\frac{1}{h_{\mathrm{can}}} h_{\mathrm{cw}-f}\left(T_{\mathrm{cw}}-T_{f}\right)+\frac{1}{h_{\mathrm{can}}} h_{\mathrm{if}-f}\left(T_{\mathrm{if}}-T_{f}\right)
\end{gathered}
$$

with

$$
\frac{\partial \tau}{\partial x}=-\frac{C_{f}}{2} \rho_{f} V_{f}^{2} \frac{p}{S}=-\frac{C_{f}}{2} \rho V_{f}^{2} \frac{4}{D_{H}}
$$

and $j_{q}=-\lambda_{f} \cdot \operatorname{grad}\left(T_{f}\right)$.

The thermal expansion coefficient is given by $\beta_{c}=1 / \rho \times$ $\partial \rho /\left.\partial T\right|_{P}[\underline{44}, \underline{45}]$ and Darcy's law $\left(\dot{m}_{w}=\kappa \times \frac{\Delta P}{e_{w}} \times A_{w} \times \frac{\rho_{f y}}{\mu_{f y}}\right)$ is needed to take into account the loss of mass flow rate through a porous wall of the combustion chamber (when applicable).

\section{Chemistry of Pyrolysis and Transport Equation of Compounds}

The transport equation [Eq. (4)] is solved for chemical species inside the cooling channel:

$$
\frac{\partial\left(\rho_{f} Y_{i}\right)}{\partial t}+\frac{\partial\left(\rho_{f} V_{f} Y_{i}\right)}{\partial x}=\rho_{f} w_{i}-\frac{1}{h_{\mathrm{can}}} \rho_{f y} V_{f y} Y_{i}
$$

The mass fractions of compounds are calculated thanks to this species balance. Fluid is treated as a single phase flow in a cross section of the channel. The main phase is chosen depending on the physical state of each component [46]. The net production rates $\left(w_{i}\right)$ of species $i$ are determined using a complete validated pyrolysis mechanism for $n$-dodecane (1185 reactions and 153 species, designed by the French laboratory DCPR) [33] solved with a toolbox for MATLAB named CANTERA [47], which is similar to the code CHEMKIN-II written in FORTRAN language. This accounts for

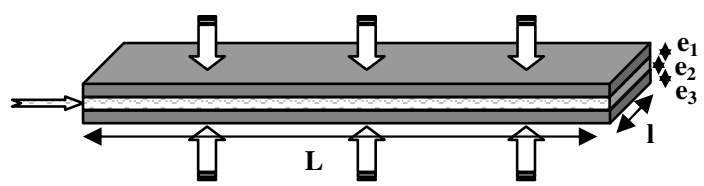

Fig. 3 Schematic test case of fluid flow between two parallel walls.

temperature and pressure dependence of pyrolysis. Then, it can influence temperature fluid because of endothermic effects.

\section{E. Physical Properties of Fluid}

Details of the following section can be found in [46]. Dynamic viscosity and thermal conductivity are computed using Guo et al.'s method [48], which takes into account the fluid composition and the supercritical fluid specificity linked to the pressure and the temperature. The method uses the Peng-Robinson equation of state and results in solving a polynomial equation of third degree in viscosity or conductivity. CHEMKIN polynomials are used to calculate the heat capacity of each species. These are then corrected with a supplementary term [Eq. (5)] which is determined thanks to the Lee-Kesler tables [41]. An additional correction is brought at the liquid-vapor transition by the mixture enthalpy divided by the transition temperature [46]. Computation of density has been explained in Sec. II.C:

$$
\left(\frac{C_{P}-C_{P}^{0}}{R}\right)=\left(\frac{C_{P}-C_{P}^{0}}{R}\right)^{(0)}+\omega\left(\frac{C_{P}-C_{P}^{0}}{R}\right)^{(1)}
$$

\section{Validation Test Cases}

Multiple validations have already been conducted with various experimental, analytical, and numerical data [46]. Two of the most recent validation cases are presented here: on a numerical point of view with the commercial CFD-ACE software and on an experimental point of view with the COMPARER test bench. Velocities of fluid flow inside the cooling channel are expected to be subsonic (a few tens of $\mathrm{m} \cdot \mathrm{s}^{-1}$ ). Because of the low mass flow rate available on the COMPARER test bench, velocities for the present validation cases are less than $1 \mathrm{~m} \cdot \mathrm{s}^{-1}$.

\section{A. Numerical Data}

Because no cooled engine exists presently and because no adapted software is suitable for such validations, RESPIRE is only used with the cooling channel, not with the complete vehicle. Three test cases are presented, two in steady state and one transient. The geometric configuration (Fig. 3) under study is a two-dimensional channel $\left(L=1 \mathrm{~m} ; e_{1}=e_{2}=e_{3}=3 \times 10^{-3} \mathrm{~m}\right)$ composed of two parallel walls. The mass flow rates used for each test case are reported in Table 1. In order to have simple test cases with discrepancies easier to analyze, fluid properties are fixed and given in Table 2 as the ones for solid walls. Pyrolysis chemistry is not taken into account. A space step for CFD-ACE of $5 \times 10^{-3} \mathrm{~m}$ in the fluid direction is chosen; the one in the orthogonal way is $10^{-4} \mathrm{~m}$.

\section{B. Experimental Data}

A dedicated test bench for the COMPARER project (Fig. 4) has been designed for the $n$-dodecane pyrolysis under supercritical conditions $(1900 \mathrm{~K}, 8 \mathrm{MPa})$. A schematic representation of the

Table 1 Summarized data of numerical validation test cases

\begin{tabular}{lccc}
\hline \hline & \multicolumn{2}{c}{ Steady-state cases } & \multirow{2}{*}{ Transient case } \\
\cline { 2 - 3 } & Case 1 & Case 2 & \\
\hline Mass flow rate, $\mathrm{g} \cdot \mathrm{s}^{-1}$ & 0.1 & 0.05 & 0.1 then 0.05 \\
Inlet fluid temperature, $\mathrm{K}$ & 600 & 600 & 600 \\
Inlet fluid pressure, MPa & 3.5 & 3.5 & 3.5 \\
Isothermal wall temperature, $\mathrm{K}$ & 1400 & 1400 & 1400 \\
\hline \hline
\end{tabular}


Table 2 Fixed fluid and solid properties for validation test cases

\begin{tabular}{lcccc}
\hline \hline & $\begin{array}{c}\lambda \\
\mathrm{W} \cdot \mathrm{m}^{-1} \cdot \mathrm{K}^{-1}\end{array}$ & $\begin{array}{c}c_{p} \\
\mathrm{~J} \cdot \mathrm{kg}^{-1} \cdot \mathrm{K}^{-1}\end{array}$ & $\begin{array}{c}\rho \\
\mathrm{kg} \cdot \mathrm{m}^{-3}\end{array}$ & $\begin{array}{c}\mu \\
\mathrm{Pa} \cdot \mathrm{s}\end{array}$ \\
\hline Solid & 30 & 1500 & 2000 & $-\overline{-}$ \\
Fluid & 0.0879 & 3342 & 475 & $106.8 \times 10^{-6}$ \\
\hline \hline
\end{tabular}

overall experimentation is proposed (Fig. 5). The fuel, $n$-dodecane, is pumped out of the tank and injected at controlled pressure and mass flow rate into a continuous chemical reactor placed into the furnace. Depending on the fixed furnace temperature, pyrolysis products, which are received at ambient conditions inside the liquid/gas splitter, are separated and gas phase species are analyzed by a gas chromatograph (GC). Experimental data, mainly subcritical vapor, have been obtained for code validation at different stable points in pressure and temperature for a given mass flow rate (Table 3 ). The given molar fractions in the gas phase are the ones of calibrated species. Their accuracies are estimated at $0.1 \%$ in mole fraction. The other species are mainly butane and butene. The maximum furnace temperature is approximately the maximum one for fluid because of high residence times evaluated from 30 to $80 \mathrm{~s}$ depending on the conditions. The mass gasification rate, in percent, is the mass of gas at the channel outlet under ambient conditions divided by the mass of injected fuel into the channel during the test.

\section{Results and Discussion}

\section{A. Steady-State Validation Cases}

Strong heterogeneities of fluid flow and thus heat transfer are shown in Figs. $6-8$ by 2 -D calculations (CFD-ACE). Because of the one-dimensional approach of RESPIRE, results need to be well understood.

Into the present channel, a mass flow rate of $0.1 \mathrm{~g} \cdot \mathrm{s}^{-1}$ or $0.05 \mathrm{~g} \cdot$ $\mathrm{s}^{-1}$ corresponds to a fluid velocity of $8.772 \times 10^{-3} \mathrm{~m} \cdot \mathrm{s}^{-1}$, respectively, $4.386 \times 10^{-3} \mathrm{~m} \cdot \mathrm{s}^{-1}$. Residence times are about 114 and $228 \mathrm{~s}$ for these two cases. The Reynolds number depends on the semi-empirical correlations used. Indeed, RESPIRE uses the Colebrook formula with pin fins because the overall model has been designed for the vehicle in which the cooling channel integrates such

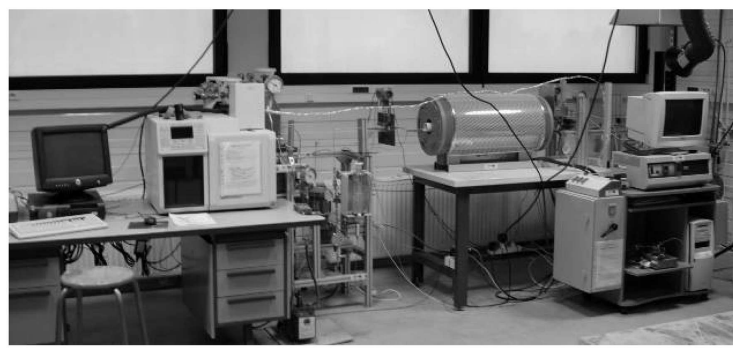

Fig. 4 Experimental COMPARER bench for the test of measuring methods on pyrolyzed hydrocarbon.

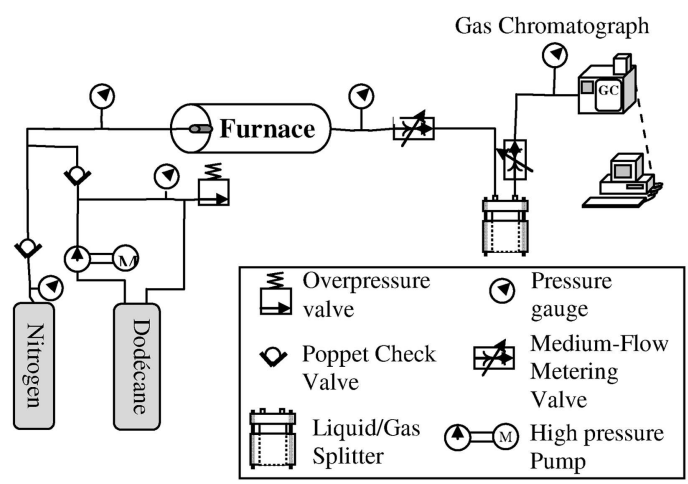

Fig. 5 Schematic representation of the COMPARER bench for supercritical endothermic fuel pyrolysis.
Table 3 Experimental data of gas analysis: mole fraction (\%) measured at the reactor outlet

\begin{tabular}{lcc}
\hline \hline & Case 1 & Case 2 \\
\hline Maximum furnace temperature, $\mathrm{K}$ & 1040 & 1100 \\
Chemical reactor pressure, Mpa & 1.2 & 1.0 \\
Fuel mass flow rate, $\mathrm{g} \cdot \mathrm{s}^{-1}$ & 0.1 & 0.05 \\
Molar fractions sum & 79.5 & 72.1 \\
Conversion rate & $60 \%$ & $75 \%$ \\
Mass gasification rate & $17 \%$ & $100 \%$ \\
$\mathrm{H} 2$ & 1.4 & $<0.01$ \\
$\mathrm{CH} 4$ & 15.4 & 19.3 \\
$\mathrm{C} 2 \mathrm{H} 2$ & $<0.01$ & $<0.01$ \\
$\mathrm{C} 2 \mathrm{H} 4$ & 26.8 & 25.4 \\
$\mathrm{C} 2 \mathrm{H} 6$ & 15.4 & 11.3 \\
$\mathrm{C} 3 \mathrm{H} 6$ & 14.8 & 14.2 \\
C3H8 & 5.7 & 1.9 \\
Noncalibrated data & 20.5 & 27.9 \\
\hline \hline
\end{tabular}

geometry, as shown in Fig. 2 . Because CFD-ACE uses a semiinfinite 2-D channel, its hydraulic diameter is

$$
D_{H}=\frac{4\left(l \times e_{2}\right)}{\left[2\left(l+e_{2}\right)\right]} \underset{l \rightarrow \infty}{\longrightarrow} 2 e_{2}=6 \times 10^{-3} \mathrm{~m}
$$

whereas RESPIRE has one of $D_{H}=4.36 \times 10^{-3} \mathrm{~m}$ for the pin fins geometry. For CFD-ACE this gives a Reynolds number of 234 against 170 for RESPIRE. Both models present a Reynolds number divided by a factor 2 for the second steady-state case, respectively, 117 and 85 . The pressure losses are less than $15 \mathrm{~Pa}$. In the onedimensional approach, a convective coefficient is considered between the fluid and the wall but it is not possible for CFD-ACE because it takes the boundary layer into account. To compare such a coefficient, the heat flux density between solid and fluid for CFDACE has been divided by the difference of the wall temperature and the fluid temperature at the center. Figure 6 illustrates the first steady-

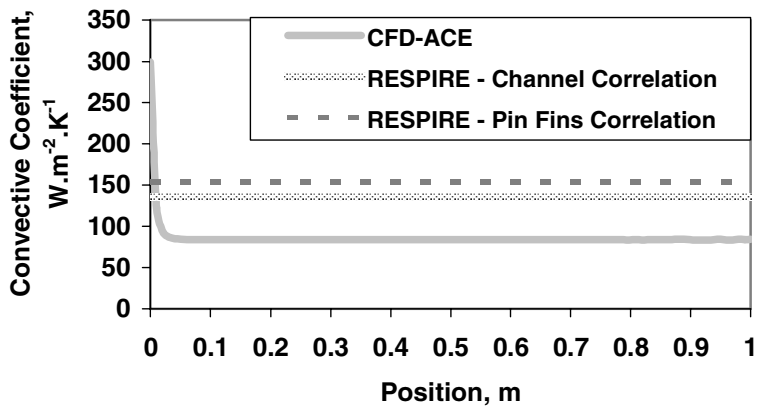

Fig. 6 Discrepancies between convective coefficient calculation ways for the first steady-state case.

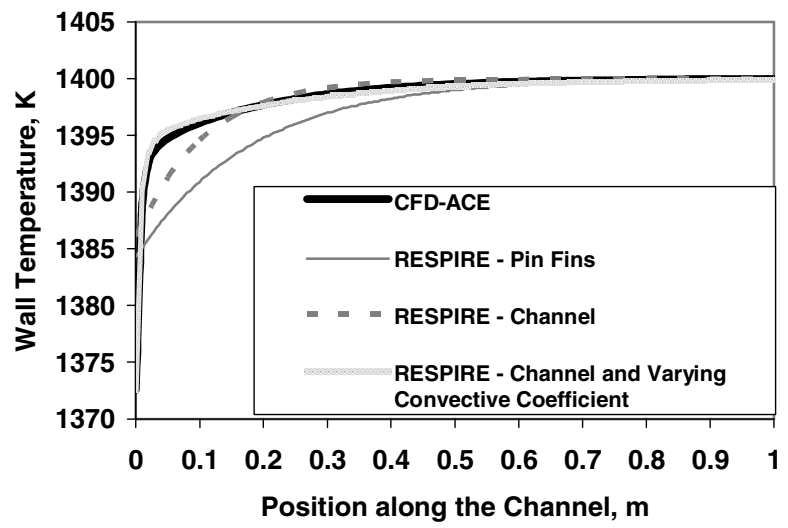

Fig. 7 Temperature of the wall in contact with fluid for the first steadystate case. 


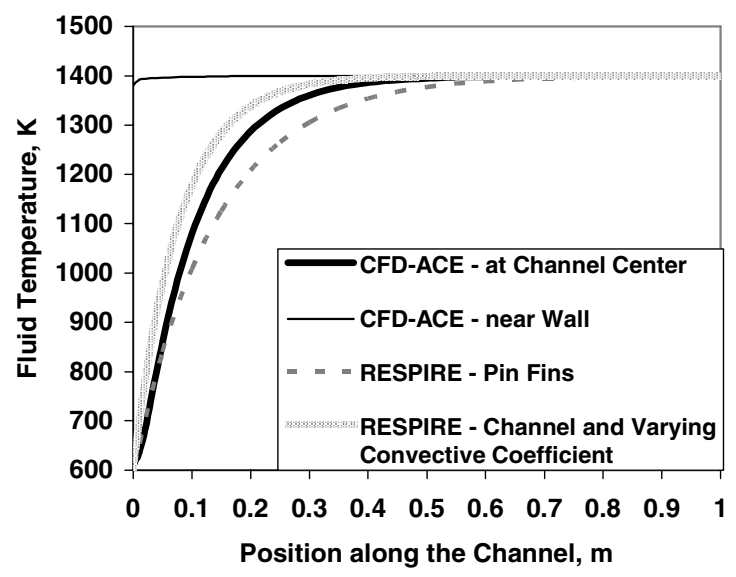

Fig. 8 Fluid temperatures for the second steady-state test case.

state case of the limitation of a 1-D model because it could not take into account a varying flow along the channel with some fixed parameters. The fluid flows from 0 to $1 \mathrm{~m}$ and from the left side to the right one. As density and mass flow rate are fixed, RESPIRE has a constant convective coefficient contrary to a 2-D approach. The one of CFD-ACE is varying depending on the momentum and thermal boundary layers. The influence of the hydraulic diameter, calculated with pin fins or for channel correlation, and the one of convective coefficient, which is constant or not along the channel, are clearly shown on the wall temperature (Fig. 7). It explains the discrepancies of temperature between the two compared models: less than $2 \%$ for wall temperatures and up to $15 \%$ for fluid temperature (Fig. 8). The high differences in fluid temperature are due to the 1-D approach, which considers an average fluid temperature for each position along the channel, whereas CFD-ACE takes a temperature profile into account at each $x$-axis position. The RESPIRE fluid temperature is composed between the one at the center of the channel for CFD-ACE and the one near the wall. The influence of the boundary layer at the channel inlet is important until its setting-up along the channel. This is the main limitation of the 1-D approach. Nevertheless, both codes give exactly the same value at the channel outlet (discrepancy lower than $0.05 \mathrm{~K}$ ), and this shows the good agreement of RESPIRE for a long flow with an established boundary layer.

Another important point to study is the heat flux exchanged between the wall of the channel and the fluid. To heat the fluid from 600 to $1400 \mathrm{~K}$, the necessary heat flux is $\Phi=\dot{m} C_{p} \Delta T=267.36 \mathrm{~W}$ for the $0.1 \mathrm{~g} \cdot \mathrm{s}^{-1}$ test case and $133.68 \mathrm{~W}$ for the other steady-state case. It is possible to compute the convective heat flux from the walls to the fluid: $\Phi(x)=h_{\mathrm{cw}-f}(x) A_{\mathrm{cw}, \mathrm{step}}\left[T_{\mathrm{cw}}(x)-T_{f}(x)\right]$ where $A_{\mathrm{cw}, \text { step }}$ is the convective surface of the cold wall for one space step. Then, the total heat flux is the sum of fluxes on each cell and it is determined as

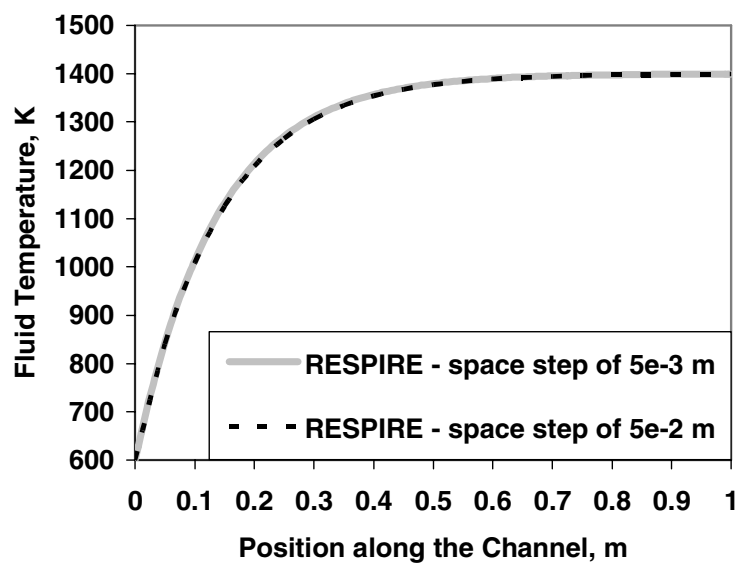

Fig. 9 Fluid temperatures for the second steady-state test case.

$$
\Phi=\sum_{i=1}^{\text {cell }} \Phi_{i}=\sum_{i=1}^{\text {cell }} \frac{\Phi\left(x_{i}\right)+\Phi\left(x_{i}+\Delta x\right)}{2}
$$

If CFD-ACE gives a heat flux of $133.8 \mathrm{~W}$ for the second test case, RESPIRE gives a heat flux of $146 \mathrm{~W}$ for a space step of $5 \times 10^{-2} \mathrm{~m}$. This value decreases to $142 \mathrm{~W}$ for $10^{-2} \mathrm{~m}$ and to $136 \mathrm{~W}$ for $10^{-3} \mathrm{~m}$. This trend is just the result of the space step when calculating the heat flux because the higher the space step, the less suitable is the average between two points of calculations. This point is only due to data posttreatment because values of fluid temperature are almost exactly the same, independently of space step (Fig. 9). The residual differences for $10^{-3} \mathrm{~m}\left(136 \mathrm{~W}\right.$ versus $\left.133.68^{-} \mathrm{W}\right)$ are due to approximated temperature (one significant number) values used to compute this heat flux. In conclusion, as the space step does not affect the pyrolysis results, it does not necessarily need to be reduced to a lowest value, except if a great accuracy for the heat flux is wanted.

\section{B. Transient Validation Case}

The present case starts from the first steady-state case conditions: after stabilization, it changes suddenly to the second test mass flow rate and it computes until the equilibrium is reached. As the two preceding cases, the full case is laminar. The sudden flow rate change is assumed to not create turbulence. Because of long residence times, a time of $300 \mathrm{~s}$ is chosen before and after the flow rate change to be sure to obtain steady-state conditions. As equilibrium states of the transient case are exactly equal to the steady-state ones, values are not presented here. Figure 10 compares the RESPIRE a) data to those of CFD-ACE b). The fluid temperature of CFD-ACE data is the one at the center of the channel for each abscissa. Qualitative time evolutions are in good agreement and quantitative discrepancies at

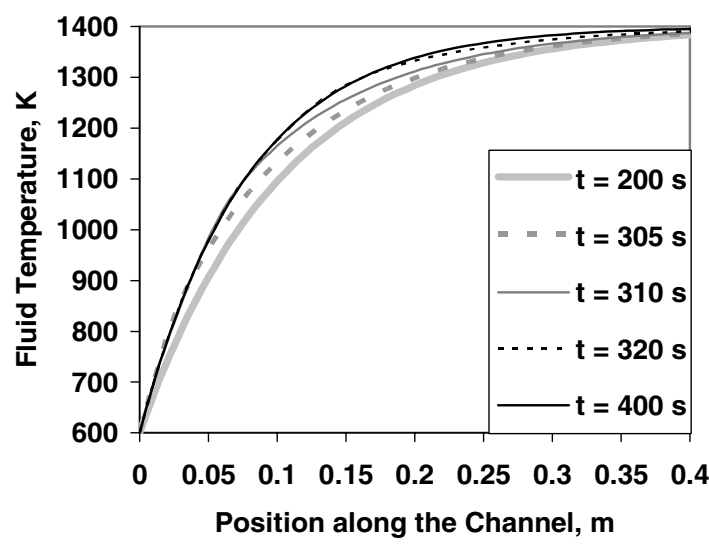

a)

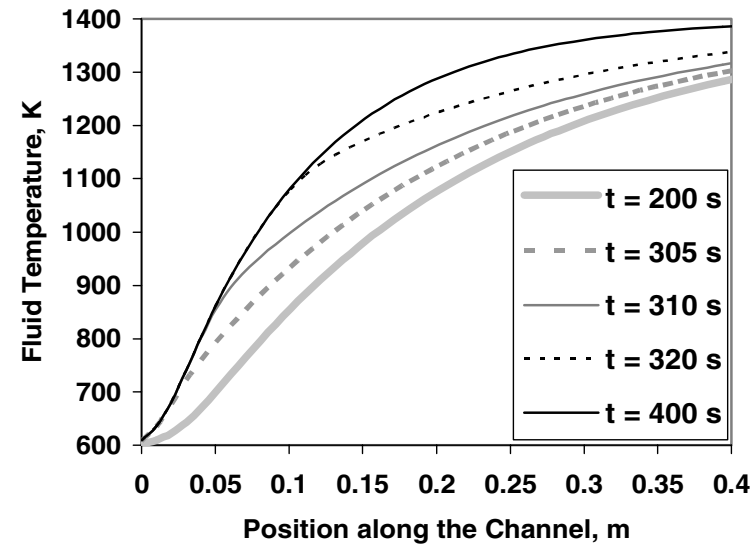

b)

Fig. 10 Fluid temperature evolution inside the channel for the transient case: a) RESPIRE; b) CFD-ACE. 


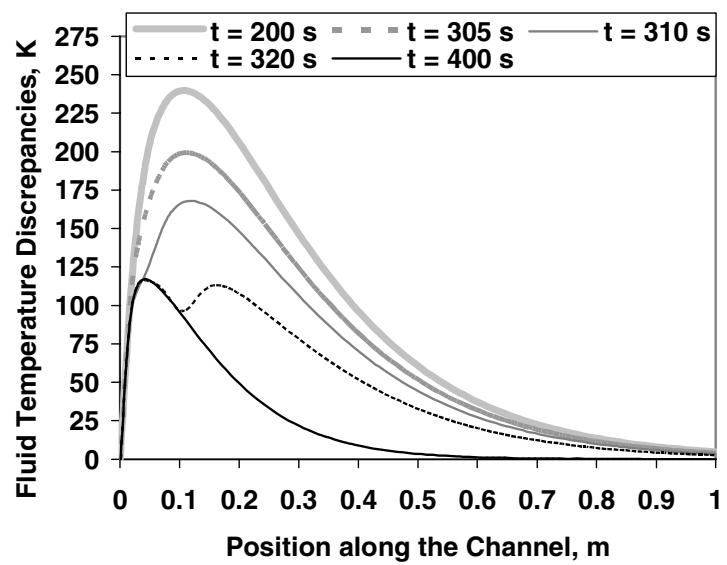

Fig. 11 Fluid temperature discrepancies between the two codes for the transient case.

steady-state conditions have already been explained. Temperature evolutions are composed between steady-state values, which was predictable. The time evolution for RESPIRE looks more linear than CFD-ACE because of the convective coefficient which is fixed for a given fluid velocity; whereas for CFD-ACE, this coefficient varies along the channel. This gives a different fluid temperature evolution depending on the position into the channel. Discrepancies between the two codes are plotted for the five values of time (Fig. 11). This shows that numerical data are in really good agreement at the channel outlet where momentum and thermal boundary layers are established.

The evolution of velocity is of great interest. Because the fluid is treated as incompressible, the density is constant, the sudden change in flow rate has for a consequence to divide by a factor 2 the velocity,

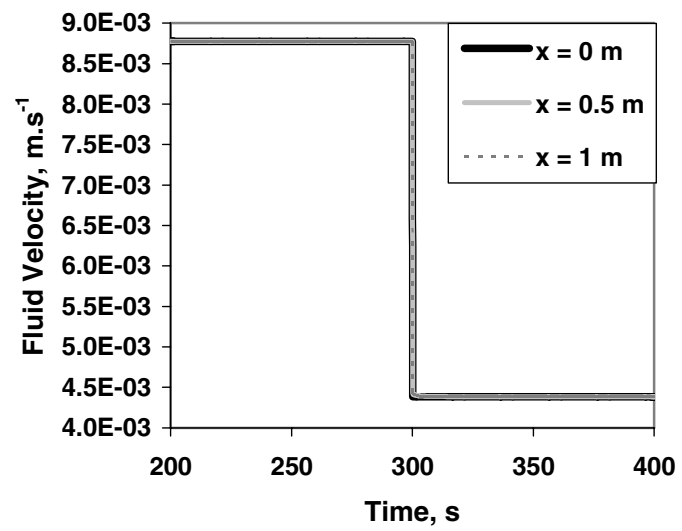

Fig. 12 RESPIRE time evolution of fluid velocity in incompressible flow. instantaneously along the channel. This is given by writing the derivative of fluid mass in the whole channel (no accumulation term in incompressible flow):

$$
\frac{d m}{d t}=\frac{d(\rho \mathrm{Vol})}{d t}=\dot{m}_{\text {inlet }}-\dot{m}_{\text {outlet }}
$$

where "Vol" is the volume of the channel. As the channel is not deformable,

$$
\frac{d(\rho \mathrm{Vol})}{d t}=0
$$

Eq. (6) is rewritten as

$$
\dot{m}_{\text {inlet }}-\dot{m}_{\text {outlet }}=\left.\rho S V\right|_{\text {inlet }}-\left.\rho S V\right|_{\text {outlet }}=\rho S\left(V_{\text {inlet }}-V_{\text {outlet }}\right)
$$

Consequently, the velocity at the entrance and at the exit of the channel is equal at each time step. This result is perfectly shown in Fig. 12 .

\section{Chemical Validation with Experimental Cases}

RESPIRE has been used to compute some experimental test cases run on the COMPARER test bench. The simple geometry of the bench allows easy numerical simulations. Inlet fluid temperature/ pressure/flow rate and external wall surface temperatures are used as boundary conditions. Because only calibrated gas phase species at ambient conditions are studied and quantified, only seven species are conserved after finished calculations. Their molar fractions sum is made equal to the one of the experimentally quantified species. Results are presented by Fig. 13 a for case 1 and Fig. 13 b for case 2. Discrepancies are mainly due to the geometric configuration as pin fins are used in RESPIRE whereas a cylinder tube is experimentally used. Furthermore, the external wall temperature profile is supposed to be equal to the furnace temperature profile measured during the test but this implies a relative error. No other data such as outlet fluid temperature or velocity are available to compare RESPIRE to COMPARER data.

\section{Conclusions}

For the COMPARER project, a one-dimensional transient model has been programmed to simulate the scramjet active cooling and to determine the mixture composition at the cooling channel outlet. A complete detailed mechanism with 1185 reactions and 153 species has been used. Equations have been presented in this work and the main possible validations at this time, depending on the available data, have been conducted for most of the different identified parts. RESPIRE is quantitatively validated considering the onedimensional modeling as differences to the 2-D model are understood. CFD-ACE uncertainties are supposed to be lower than 1 deg whereas the ones of RESPIRE are considered to be lower than 10 deg. Although RESPIRE presents an accuracy lower than

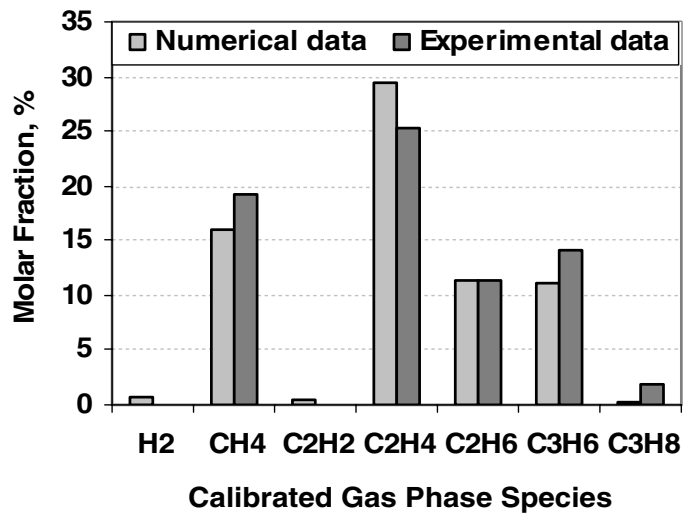

b)

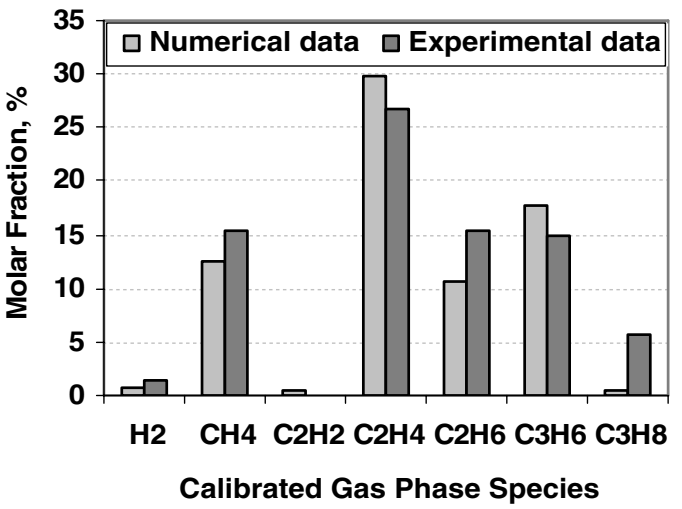

Fig. 13 Chemical composition computed with RESPIRE, comparison to experimental data. 
commercial CFD software, it is satisfactory for engineering applications. Thermal and hydraulic time evolutions are reasonable and quantitative results are adequate for a 1-D model, used as a predimensioning tool. The stability of RESPIRE and its sensitivity to spatial step is ensured, as is the convergence reliability. Through all the calculated cases, its adaptability to various configurations has been proved. The low computation cost of RESPIRE makes it suitable for engineering needs. It needs one night of calculations for simulating $1 \mathrm{~min}$ with the overall vehicle of $1 \mathrm{~m}$ long with appropriate spatial and time steps. Identified limits of the code are due to its one-dimensional structure. For example, for laminar flows presenting 2-D hydraulic and thermal effects, temperature discrepancies as high as $30 \%$ may arise. This has been partially corrected by the use of natural convection inside the reactor, but this alone is not sufficient. The code is preferably designed for high Reynolds number flows with an established boundary layer, which is expected in typical scramjet cooling channels. Nevertheless, to our knowledge, this is the first transient coupled model for such a geometric configuration, which considers thermal and mass transfers and chemical reactions under liquid, gas, and supercritical conditions.

This new validation completes the whole set of steady state and transient validations on the cooling channel in the main related field (fluid mechanics, heat transfer in solid and fluid, chemical reactions, supercritical state, and fluid properties). The validation of RESPIRE should continue on phenomena through the porous wall. This model should help to build a cooling strategy after a complete validation of the combustion chamber and a propulsion assessment. We hope to use RESPIRE as a predicting and controlling tool for scramjet cooling management. In this regard, it could test measuring methods on the hydrocarbon fuel such as giving infrared spectroscopic data during calculations. The dedicated experimental test bench can provide further validation data on chemical aspects and on the dynamic response of inlet time variations. Furthermore, an experimental combustion study is expected to be conducted in 2007 on premixed and diffusion flames for the pyrolyzed fluid. These data should bring additional validation cases. At this time, we are currently conducting a parametric study on coking since our experiments result in an elevated rate of coke deposition, which decreases the abilities of the bench.

\section{Acknowledgments}

The authors would like to sincerely thank E. Daniau, S. Bernard, E. Dufour, and F. Falempin for their permanent support involving this project. The present work has been realized with contributions from the "Conseil Général du Cher (18)," the "Conseil Régional du Centre," the Fonds de Restructuration de la Défense, the Fonds Européen de Developpement Régional, the Fond Social Européen, and from MBDA-France. The good evolution of the COMPARER project was made possible thanks to the contribution of $\mathrm{Y}$. Parmantier, project manager and coordinator of the "Pôle Capteurs et Automatismes" of Bourges.

\section{References}

[1] Fry, R. S., "A Century of Ramjet Propulsion Technology Evolution," Journal of Propulsion and Power, Vol. 20, No. 1, Jan.-Feb. 2004, pp. $27-58$

[2] McClinton, C. R., "X-43-Scramjet Power Breaks the Hypersonic Barrier Dryden Lectureship in Research for 2006," AIAA 2006-1, 2006.

[3] Andrews, E. H., "Scramjet Development and Testing in the United States," AIAA 2001-1927, 2001.

[4] Curran, E. T., "Scramjet Engines: The First Forty Years," Journal of Propulsion and Power, Vol. 17, No. 6, Nov.-Dec. 2001, pp. 11381148.

[5] Falempin, F., "High-Speed Airbreathing Propulsion: French Activities," AIAA Paper 2002-5232, 2002.

[6] Falempin, F., and Serre, L., "LEA Flight Test Program-Status in 2004," AIAA 2004-3344, 2004

[7] Shikhman, Y. M., Vinogradov, V. A., Yanovski, L. S., Stepanov, V. A., Shlyakotin, V. E., and Pen'kov, S. N., "The Demonstrator of
Technologies-Dual Mode SCRAMJET on Hydrocarbon Endothermic Fuel," AIAA Paper 1787, 2001

[8] Boselli, L., Giraudo, T., Massot, A., and Talbot, B., "Dual-Fuel Advanced High-Speed Ramjets," AIAA Paper 2002-5214, 2002.

[9] Bouchez, M., Beyer, S., and Cahuzac, G., "Ptah-Socar Fuel-Cooled Composite Materials Structure for Dual-Mode Ramjet and Liquid Rocket Engines," AIAA Paper 2004-3653, 2004.

[10] Bouchez, M., and Beyer, S., "Ptah-Socar Fuel-Cooled Composite Materials Structure for Dual-Mode Ramjet and Liquid Rocket Engines —2005 Status," AIAA Paper 2005-3434, 2005.

[11] Beyer, S., Schmidt, S., Peres, P., and Bouchez, M., "Advanced Ceramic Matrix Composite Materials for Current and Future Propulsion System Applications," AIAA Paper 2005-3644, 2005.

[12] Townend, T. H., "Domain of the Scramjet," Journal of Propulsion and Power, Vol. 17, No. 6, Nov.-Dec. 2001, pp. 1205-1213

[13] Powell, O. A., Edwards, J. T., Norris, R. B., Numbers, K. E., and Pearce, J. A., "Development of Hydrocarbon-Fueled Scramjet Engines: The Hypersonic Technology (Hytech) Program," Journal of Propulsion and Power, Vol. 17, No. 6, Nov.-Dec. 2001, pp. 1170-1176.

[14] Edwards, T., and Meyer, M. L., "Propellant Requirements For Future Aerospace Propulsion Systems," AIAA Paper 2002-3870, 2002.

[15] Huang, H., Sobel, D. R., and Spadaccini, L. J., "Endothermic Heat-Sink of Hydrocarbon Fuels for Scramjet Cooling," AIAA Paper 2002-3871, 2002.

[16] Daniau, E., Bouchez, M., Bounaceur, R., Battin-Leclerc, F., Marquaire, P. M., and Fournet, R., "Contribution to Scramjet Active Cooling Analysis Using N-Dodecane Decomposition Model as a Generic Endothermic Fuel," AIAA Paper 2003-6920, 2003.

[17] Thomas, S. R., and Guy, R. W., "Increase Capabilities of the Langley Mach 7 Scramjet Test Facility," AIAA Paper 1982-1240, 1982.

[18] Voland, R. T., Huebner, L. D., and Mcclinton, C. R., "X-43a Hypersonic Vehicle Technology Development," Acta Astronautica, Vol. 59, Nos. 1-5, July-Sept. 2006, pp. 181-191.

[19] Mitani, T., Ueda, S., Tani, K., Sato, S., Miyajima, H., Matsumoto, M., and Yasu, S., "Validation Studies of Scramjet Nozzle Performance," Journal of Propulsion and Power, Vol. 9, No. 5, Sept.-Oct. 1993, pp. 725-730.

[20] Kouchi, T., Mitani, T., and Masuya, G., "Problems of Numerical Diffusion Found in Scramjets," AIAA Paper 2005-3216, 2005.

[21] Kanda, T., "Study of an Airframe-Integrated Scramjet Engine System," AIAA Paper 2000-3705, 2000.

[22] Kanda, T., Masuya, G., Ono, F., and Wakamatsu, Y., "Effect of Film Cooling/Regenerative Cooling on Scramjet Engine Performances," Journal of Propulsion and Power, Vol. 10, No. 5, Sept.-Oct. 1994, pp. 618-624.

[23] Tsujikawa, Y., and Northam, G. B., "Effects of Hydrogen Active Cooling on Scramjet Engine Performance," International Journal of Hydrogen Energy, Vol. 21, No. 4, 1996, pp. 299-304.

[24] Dinkelmann, M., Wächter, M., and Sachs, G., "Modelling and Simulation of Unsteady Heat Transfer for Aerospacecraft Trajectory Optimization," Mathematics and Computers in Simulation, Vol. 53, Nos. 4-6, Oct. 2000, pp. 389-394.

[25] Kanda, T., and Kudo, K., "Conceptual Study of a Combined-Cycle Engine for an Aerospace Plane," Journal of Propulsion and Power, Vol. 19, No. 5, Sept.-Oct. 2003, p. 6176.

[26] Wassel, A. T., Lssacci, F., and Van Griethuysen, V., "An Integrated Modelling Approach for Hypersonic Aircraft Thermal Management," AIAA Paper 1995-6022, 1995.

[27] Oberkampf, W. L., and Trucano, T. G., "Verification and Validation in Computational Fluid Dynamics," Progress in Aerospace Sciences, Vol. 38, No. 3, April 2002, pp. 209-272.

[28] White, M. E., Drummond, J. P., and Kumar, A., "Evolution and Application of CFD Techniques for Scramjet Engine Analysis," Journal of Propulsion and Power, Vol. 3, No. 5, Sept.-Oct. 1987, pp. 423-439.

[29] Molvik, G. A., Bowlestand, J. V., and Huynh, L. C., "Analysis of a Hydrocarbon Scramjet with Augmented Preburning," AIAA Paper 1992-3425, 1992

[30] Benay, R., Chanetz, B., and Délery, J., "Code Verification/Validation with Respect to Experimental Data Banks," Aerospace Science and Technology, Vol. 7, No. 4, June 2003, pp. 239-262.

[31] Ben-Arosh, R., and Natan, B., "Theoretical Study of a Solid Fuel Scramjet Combustor," Acta Astronautica, Vol. 45, No. 3, 1999, pp. 155-166.

[32] Mitani, T., and Kouchi, T., "Flame Structures and Combustion Efficiency Computed for a Mach 6 Scramjet Engine," Combustion and Flame, Vol. 142, No. 3, Aug. 2005, pp. 187-196.

[33] Dahm, K. D., Virk, P. S., Bounaceur, R., Battin-Leclerc, F., Marquaire, P. M., Fournet, R., Daniau, E., and Bouchez, M., "Experimental and 
Modelling Investigation of the Thermal Decomposition of nDodecane," Journal of Analytical and Applied Pyrolysis, Vol. 71, No. 2, June 2004, pp. 865-881.

[34] Ward, T. A., Ervin, J. S., Striebich, R. C., and Zabarnick, S., "Simulations of Flowing Mildly-Cracked Normal Alkanes Incorporating Proportional Product Distributions," Journal of Propulsion and Power, Vol. 20, No. 3, May-June 2004, pp. 394-402.

[35] Daniau, E., Bouchez, M., and Gascoin, N., "SCRAMJET Active Cooling Analysis Using $n$-Dodecane as a Generic Endothermic Fuel," Thermochemical Processes in Plasma Aerodynamics, Radio-Avionika, Moscow, 2004, ISBN 5-888770-16-7.

[36] Gascoin, N., Gillard, P., Touré, Y., Bernard, S., Daniau, E., and Bouchez, M., "Mesures et Contrôle de Paramètres Pertinents pour la Régulation d'un Statoréacteur Mixte Refroidi," Troisième Rencontre Capteurs, Pole Capteur \& Automatisme, Bourges, France, 21 Octobre 2004,

[37] Gascoin, N., Gillard, P., Touré, Y., Bernard, S., Daniau, E., and Bouchez, M., "Modélisation Hydraulique et Thermique d'un Fluide Supercritique avec Pyrolyse dans un Canal Chauffé: Prédimensionnement d'une Etude Expérimentale," Congrès Français de Thermique, SFT 2005, Edition Société Française de Thermique, Paris, 30 mai2 juin 2005, ISBN 2-905267-43-7.

[38] Dufour, E., and Bouchez, M., "Semi-Empirical and CFD Analysis of Actively Cooled Dual-Mode Ramjets," AIAA Paper 5126, 2002.

[39] Gascoin, N., Gillard, P., Bernard, S., Bouchez, M., Daniau, E., Dufour, E., and Touré, Y., "Numerical and Experimental Validation of Transient Modelling for Scramjet Active Cooling with Supercritical
Endothermic Fuel," AIAA Paper 2006-4028, 2006

[40] Leleu, R., “Transferts de Chaleur,” Techniques de l'Ingénieur, J1080.

[41] Gosse, J., "Constantes Thermodynamiques: Données Thermodynamiques des Fluides," Techniques de l'Ingénieur, K535.

[42] Daugherty, R. L., Franzini, J. B., and Finnemore, E. J., Fluid Mechanics with Engineering Applications, Mechanical Engineering Series, SI Metric Edition, McGraw-Hill, Singapore, metric ed., 1989, ISBN 0-07100405-X

[43] Le Neindre, B., "Effets des Hautes et Très Hautes Pressions," Techniques de l'Ingénieur, K484.

[44] Bejan, A., Convection Heat Transfer, 3rd ed., Wiley, New York, 2004.

[45] Bianchi, A-M., Fautrelle, Y., and Etay, J., Transferts Thermiques, Presses Polytechniques et Universitaires, Romandes, 2004.

[46] Gascoin, N., Gillard, P., Touré, Y., Daniau, E., Bernard, S., and Bouchez, M., "Modélisation d'un Statomixte Refroidi par Endocarburant Supercritique: Couplage Thermique-Chimie et Transferts de Matière," Récents Progrès en Génie des Procédés, Vol. 92, Lavoisier SAS, Cachan, France, 2005.

[47] Goodwin, D. G., "An Open-Source, Extensible Software Suite for CVD Process Simulation," Chemical Vapor Deposition XVI and EUROCVD 14, ECS Proceedings, Vol. 8, The Electrochemical Society, Pennington, NJ, 2003, pp. 155-162.

[48] Guo, X. Q., Sun, C. Y., Rong, S. X., Chen, G. J., and Guo, T. M., "Equation of State Analog Correlations for the Viscosity and Thermal Conductivity of Hydrocarbons and Reservoir Fluids," Journal of Petroleum Science and Engineering, Vol. 30, No. 1, June 2001, pp. 1527. 